increased nuchal translucency as a screening test for the detection of fetal chromosomal abnomalities, ] Matern Fetal Neonatal Med, 22(10): 857-62

6. Đă̆ng Lê Dung Hạnh, Nguyễn Vạn Thông (2007). Đánh giá chương trinh tầm soát hối chứng Down trong thai kỳ bằng xét nghiệm sinh hóa tại Bệnh viện Hùng Vương, Tạp chí Phụ Sản, 03-04, tr.65-79.

7. Sung-Hee Han, M.Đ., Jeong-Wook An, M.T. et al (2008). Clinical and cytogenetic findings on 31.615 mid-trimester amniocenteses, Korean JLab
Med 2008; 28: 378-85.

8. Dragoslav Bukvic, Margherita Fanelli, Guanti Ginevra, Nenad Bukvic (2011). Justifiability of amniocentesis on the basis of positive findings of triple test, ultrasound scan and advanced maternal age, Acta Medica Academica 2017; 40(1): 10-16.

9. Charlotte K Ekelund et al (2008). Impact of a new national screening policy for Down's syndrome in Denmark: population based cohort study, BMJ2008; 337: 1-7.

\title{
THỰC TRANG TUÂN THỦ VÊ SINH TAY CỦA NHÂN VIÊN Y TẾ TẠI CÁC KHOA LÂM SÀNG BỆNH VIÊ̂N PHỔI TRUNG ƯƠNG NĂM 2016
}

\section{TÓM TẮT}

Nhiễm khuẩn Bệnh viện (NKBV) là hậu quả không mong muốn trong thực hành khám, chữa bệnh và chăm sóc người bệnh. Tỷ lệ nhiễm khuẩn bệnh viện là một trong những chỉ số quan trọng phản ánh chất lượng chuyên môn của bệnh viện, liên quan đến sự an toàn của người bệnh và nhân viên y tế (NVYT); Mục tiêu: Mô tả thực trang kiến thức vê sinh tay (VST'), xác định tỷ lệ tuân thủ thực hành VisT của NVYT tại các khoa lâm sàng Bênh viên Phổi Trung ương năm 2016; Phương pháp nghiển cứu: Tiến cứu, mô tả cắt ngang; Kết quả: Tỷ lệ kiến thức VST của NVYT như sau: Giỏi, khá đạt 80,8 \%; trung bình 19,2\%. Tỷ lệ tuân thủ thực hành VST chung là 55,9\% trong đó tuân thủ theo từng đối tượng là: Bác sĩ đạt 42,3\% ĐD/KTV đạt 59,6\%, Hộ lí đạt 46.9\%. Tỷ lệ tuân thủ thực hành VST ở trình độ cao đẳng là cao nhất đạt $69,3 \%$ và thấp nhất là trình độ sau Đại học đạt 17,9\%, Khối Cấp cứu - Hồi sức tích cực cao nhất đạt $69,1 / \%$, thấp nhất là khối Nội đạt $50,6 \%$. Khoa cao nhất là khoa Hồi sức tích cực đat $72,7 \%$, thấp nhất là Ngoại Tổng hợp đạt 38.8\%; Kết luận: Tỷ lệ kiến thức của NVYT tế đat trên mức trung bình đat $73 \%$, tỷ lệ chung tuân thủ vệ sinh tay đạt $55,9 \%$, tỷ lệ bỏ lỡ cớ hô̂i VST của Bác sĩ $57,7 \%$, trong đó $77,4 \%$ bỏ Iõ cơ hội VST do chưa có phương tiện VST khi khám bệnh, chữa bệnh, chỉ còn $22,6 \%$ bỏ Iõ VST khi có phương tiện VST.

Từ khóa: Tuân thủ, Vệ sinh tay.

\section{SUMMARY \\ CURRENT SITUATION OF HAND HYGIENE COMPLIANCE OF MEDICAL STAFF IN}

\footnotetext{
${ }^{1}$ Bệnh viện Phổi Trung ương

${ }^{2}$ Hôii Lao và Bênh Phổi Việt nam

Chiu trách nhiệm chính: Hoàng Thăng Tùng

Email: hoangtungbvp@gmail.com

Ngày nhận bài: 22.10.2020

Ngày phản biện khoa học: 25.11.2020

Ngày duyệt bài: 8.12.2020
}

\author{
Hoàng Thăng Tùng1, Võ Thị Thanh ${ }^{1}$ \\ Lưu Lan Anh ${ }^{1}$, Đinh Ngọc Sỹ ${ }^{2}$

\section{CLINICAL DEPARTMENTS AT NATIONAL} \\ LUNG HOSPITAL IN 2016
}

Hospital Infection is an unintended consequence of practicing medical care and caring for patients. Hospital infection rates are one of the key indicators that reflect the quality of the hospital's expertise, relative to the safety of patients and medical staff. Objectives: Description of the knowledge with hand hygiene, surveys compliance rate of hand hygiene practices and surveys some related factors to hand hygiene compliance of medical staff at Clinical National Lung Hospital in 2016; Methods: Describe prospective analysis; Results: The rate of hand hygiene knowledge of medical staff as follows: Excellent, and good in 80.8\%; average in $19.2 \%$. Compliance rate overall hand hygiene practices is $55.9 \%$ which comply with each object is: doctors: $42.3 \%$, Nurses / technicians: $59.6 \%$, Nurse's aid: $46.9 \%$. Compliance rate of hand hygiene practices is the highest in collegiat $(69.3 \% 0$ and the lowest of postgraduate qualifications (17.9\%), Division of Emergency and Intensive Care Unit - is highest $(69,1 \%)$, the lowest $(50.6 \%)$ in $f$ the Interior departements. The Intensive Care Unit is the highest $(72.7 \%)$, the lowest was $38.8 \%$ in surgery division. Conclusions: The rate of knowledge of health care workers on an average gain reached $73 \%$, the rate of hand hygiene compliance General 55.9\%, the proportion of missed opportunities of hand hygiene Doctor. $57.7 \%, 77.4 \%$ of which miss the opportunity to hand hygiene by no means hand hygiene when medical examination, treatment and care but the patients, $22.6 \%$ missed only Hand hygiene when sanitation facilities west.

Keyword: Hand hygiene, compliance

\section{I. ĐĂT VẤN ĐỀ}

Nhiễm khuẩn Bệnh viện là hậu quả không mong muốn trong thực hành khám chữa bênh và chăm sóc người bệnh ${ }^{[1],[2]}$. Tỷ lệ NKBV là một trong những chỉ số quan trọng phản ánh chất lượng chuyên môn của bệnh viện, liên quan đến 
sự an toàn của người bệnh và NVYT ${ }^{[3]}$. Ngày nay, NKBV đang là vấn đề y tế toàn cầu do tỷ lệ mắc cao, kéo dài thời gian điều trị, tăng tỷ lệ tử vong và tăng chi phí điều trị

Tổ chức $Y$ tế thế giới (WHO) khuyến cáo "Chăm sóc sạch là chăm sóc an toàn" và "Vệ sinh tay là biện pháp đơn giản và hiệu quả nhất trong phòng ngừa NKBV", đây là biện pháp rẻ tiền, dễ thực hiện và hiệu quả nhất làm giảm thiểu tỷ lệ NKBV[8].

Tại Việt Nam Ngày 27 tháng 9 năm 2012, Bộ Y tế đã ban hành Quyết định 3671/QĐ-BYT hướng dẫn kiểm soát nhiễm khuẩn, trong đó Vệ sinh tay là một trong những biện pháp quan trọng trong Phò̀ng ngừa chuẩn ${ }^{[2]}$.

Bệnh viện Phổi Trung ương chưa có nghiên cứu nào đánh giá khảo sát việc tuân thủ vệ sinh tay cũng như tìm hiểu kiến thức vệ sinh tay của NVYT tại Bệnh viện. Xuất phát từ thực tế trên chúng tôi tiến hành nghiên cứu Đề tài "Thực trạng tuân thủ vế sinh tay của nhân viên y tế tại các khoa lâm sàng Bệnh viện Phổi Trung ương năm 2016" nhằm muc tiêu:

1. Mô tả thực trang kiến thức về VST của NVYT tế tại các khoa lâm sàng Bệnh viện Phổi Trung ương năm 2016.

2. Xác định tỷ lệ tuân thủ thực hành VST của NVYT tại các khoa lâm sàng Bệnh viện Phôi Trung ương năm 2016.

\section{II. ĐỐI TƯƠNG VÀ PHƯƠNG PHÁP NGHIÊN CỨU \\ 2.1. Đối tượng nghiên cứu}

- Tiêu chuân lưa chon: NVYT được đánh giá về kiến thức và quan sát VST thường quy tại 12 khoa Lâm sàng có người bệnh điều trị nội trú trong thời gian nghiên cứu.

- Tiêu chuấn loại trừ: NVYT không có mặt tại thời điểm đánh giá.

\section{2 Địa điểm và thời gian nghiên cứu.}

- Địa điểm nghiên cứu: Tại 12 khoa Lâm sàng Bệnh viện Phổi Trung ương có người bệnh điều trị nội trú.

- Thời gian nghiên cứu: Tháng 7 đến tháng 12 năm 2016

2.3. Thiết kế nghiên cứu. Sử dụng phương pháp mô tả cắt ngang

2.4. Cỡ mẫu, Kỹ thuật chọn mẫu.

III. KẾT QUẢ NGHIÊN CỨU

1. Tỷ lệ kiến thức vệ sinh tay

Bảng 3.1. Phân bồ tỷ lê kiến thức theo chức danh

\begin{tabular}{|c|c|c|c|c|c|c|c|}
\hline \multirow{2}{*}{ STT } & \multirow{2}{*}{ Chức danh } & \multicolumn{2}{|c|}{ Giỏi, khá } & \multicolumn{2}{c|}{ Trung bình } & \multicolumn{2}{|c|}{ Tống } \\
\cline { 3 - 8 } & & $\mathbf{N}$ & $\mathbf{T y ̉}$ lệ & $\mathbf{N}$ & Tỷ lệ & $\mathbf{N}$ & Tỷ lệ \\
\hline 1 & Bác sỹ & 57 & $\mathbf{7 3 . 5}$ & 22 & $\mathbf{2 6 . 5}$ & 79 & $\mathbf{1 0 0}$ \\
\hline 2 & DD/KTV & 171 & $\mathbf{8 4 . 2}$ & 34 & $\mathbf{1 5 . 8}$ & 205 & $\mathbf{1 0 0}$ \\
\hline
\end{tabular}

- Cõ̃ mẫu toàn thể.

- Kỹ thuật chọn mẫu: Chọn tất cả các nhân viên y tế của 12 khoa Lâm sàng đủ điều kiện theo tiêu chuẩn lựa chọn tại thời điểm đánh giá. Gồm 313 nhân viển y tế tại 12 khoa Lâm sàng có người bệnh điều trị nội trú.

2.5. Các kỹ thuật, nguyên vật liệu sử dụng trong nghiên cứu.

- Bộ câu hỏi điều tra về kiến thức vệ sinh tay.

- Phiếu quan sát thực hiện các cơ hội vệ sinh tay theo bộ công cự giám sát tuân thủ vệ sinh tay của Tổ chức $Y$ tế thế giới.

- Các kỹ thuật xác định các chỉ số nghiên cứu:

+ Thời điểm VST: là lý do cần VST.

+ Cơ hội VST: là số lần cân VST trong các hoạt động chăm sóc, điều trị để cắt đứt lan truyền mầm bệnh qua bàn tay.

+ Hành động VST: Cơ hội có VST được thực hiện theo phương pháp khử khuẩn tay bẳng cồn hoặc theo phương pháp rửa tay, nếu VST không được thực hiện khi có chỉ định, cơ hội VST được ghi nhận là "bỏ lơ".

+ Tỷ lệ tuân thủ vệ sinh tay: Được xác định bằng tổng số cơ hội có vệ sinh tay (hành động vệ sinh tay) x 100/Số cớ hội cân vệ sinh tay được quan sát.

2.6. Các phương pháp thu thập số liệu.

- Phát phiếu điều tra khảo sát kiến thức vệ sinh tay tại 12 khoa Lâm sàng.

+ Đánh giá kiến thức bằng bộ câu hỏi phát cho nhân viên y tế trả lời theo các phương án có sẵn. Chon câu trả lời đúng (20 câu) trong 10 phút. Mỗi câu trả lời được 0,5 điểm.

+ Đánh giá kiến thức theo 3 mức: Giỏi, khá: 7 - 10 điểm. Không đat: $<5$ điểm

- Quan sát trực tiểp số cơ hội vệ sinh tay mà NVYT thực hiện tại 12 khoa Lâm sàng theo 5 thời điểm khuyến cáo của Tổ chức $Y$ tế thế giới:

+ NVYT được đánh giá kiến thức VST sẽ được quan sát thực hành VST từ 2 đến 5 lần.

+ Mỗi lần giám sát thực hành sẽ đánh giá tối thiểu 1 quy trình kỹ thuật thăm khám, thủ thuật, kỹ thuâtt chăm sóc.

+ Tuân thủ VST ở NVYT được giám sát trực tiếp tại các khoa Lâm sàng, các giám sát viên là thành viên nhóm nghiên cứu và cộng tác viên đã được tập huấn về kỹ năng giám sát. 


\begin{tabular}{|c|c|c|c|c|c|c|c|}
\hline 3 & Hộ lý & 25 & $\mathbf{8 6 . 2}$ & 4 & 13.8 & 29 & 100 \\
\hline \multicolumn{2}{|c|}{ Tống } & $\mathbf{2 5 3}$ & $\mathbf{8 0 . 8}$ & $\mathbf{6 0}$ & $\mathbf{1 9 . 2}$ & $\mathbf{3 1 3}$ & $\mathbf{1 0 0}$ \\
\hline
\end{tabular}

Nhận xét: Tỷ lệ khá, giỏi về kiến thức VST đạt 80,8\%, trung bình đạt 19,2\% và không có NVYT nào không đat.

2. Tỷ lệ tuân thủ vệ sinh tay

2.1. Tỷ lể tuân thủ thức hành vê sinh tay theo chức danh

Bảng 3.2. Phân bồ tỷ lề tuân thủ thức hành theo chức danh

\begin{tabular}{|c|c|c|c|c|c|c|c|}
\hline \multirow{2}{*}{ STT } & \multirow{2}{*}{ Chức danh } & \multicolumn{2}{|c|}{ Tuân thủ } & \multicolumn{2}{|c|}{ Bỏ I ̃ } & \multicolumn{2}{|c|}{ Cơ hôi } \\
\hline & & $\mathbf{N}$ & Tỷ lệ (\%) & $\mathbf{N}$ & Tỷ lệ (\%) & $\mathbf{n}$ & Tỳ lệ (\%) \\
\hline 1 & Bác sỹ & 412 & 42.3 & 561 & 57.7 & 973 & 100 \\
\hline 2 & ĐD/KTV & 2799 & 59.6 & 1898 & 40.4 & 4697 & 100 \\
\hline 3 & Hộ lý & 205 & 46.9 & 232 & 53.1 & 437 & 100 \\
\hline & Tống & 3416 & 55.9 & 2691 & 44.1 & 6107 & 100 \\
\hline
\end{tabular}

Nhận xét: Tỷ lệ tuân thủ thực hành VST chung đạt 55,9\%. Trong đó, tỷ lệ tuân thủ thực hành VST của ĐD/KTV cao nhất đạt $59,6 \%$ và thấp nhất là Bác sỹ đạt $42,3 \%$

2.2. Tỷ lệ tuân thủ vệ sinh tay theo giới tính.

Bảng 3.3. Phân bổ tỷ lệ tuân thủ thực hành theo giới

\begin{tabular}{|c|c|c|c|c|c|c|c|}
\hline \multirow{2}{*}{ STT } & \multirow{2}{*}{ Giới tính } & \multicolumn{2}{|c|}{ Tuân thử } & \multicolumn{2}{|c|}{ Bỏ Iõ } & \multicolumn{2}{|c|}{ Co hội } \\
\hline & & $\mathbf{N}$ & Tỷ lệ (\%) & $\mathbf{N}$ & Tỷ lệ (\%) & $\mathbf{N}$ & Tỳ lệ (\%) \\
\hline 1 & Nam & 697 & 48 & 753 & 52 & 1450 & 100 \\
\hline 2 & Nữ & 2719 & 58.4 & 1938 & 41.6 & 4657 & 100 \\
\hline
\end{tabular}

Nhận xét: Tỉ lệ tuân thủ thực hành VST ở Nữ 58,4\% cao hơn Nam 48\%.

2.3. Tỷ lệ tuân thủ thực hành vệ sinh tay theo thâm niên công tác.

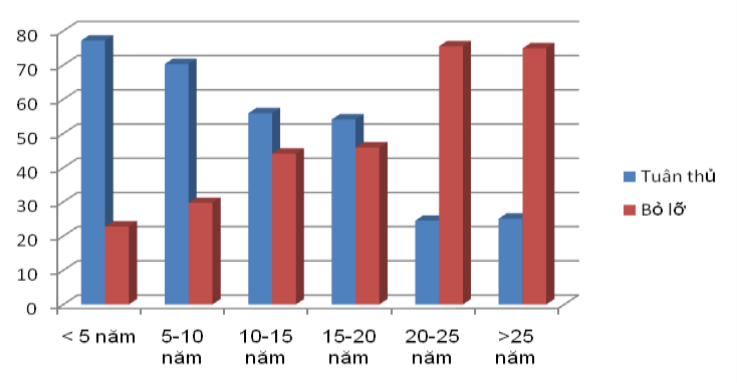

Biểu đồ 3.1. Phân bổ tỷ lệ tuân thủ thực hành theo thâm niên

Nhận xét: Tỷ lệ tuân thủ thực hành VST cao nhất ở thâm niên công tác $<5$ năm, 5-10 đạt $>$ $70 \%$ và thấp nhất ở thâm niên $20-25$ năm và $>25$ năm đạt $<26 \%$.

2.4. Tỷ iệ tuân thủ thực hành vệ sinh tay theo trình độ

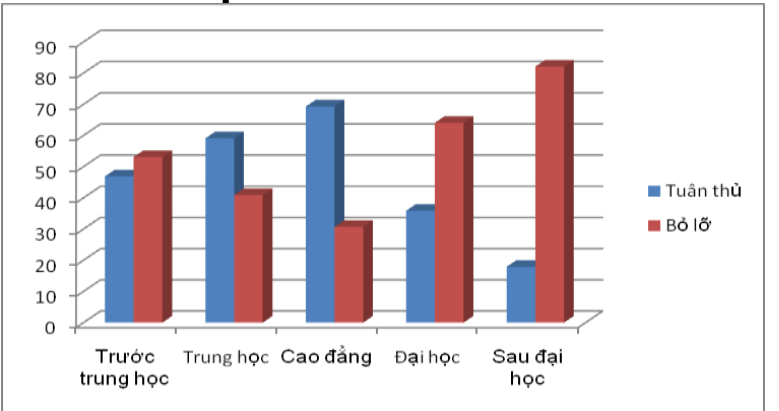

Biểu đồ 3.2. Phân bổ tỷ lệ tuân thủ thực hành theo trinh độ
Nhận xét: Tỷ lệ tuân thủ thực hành VST ở trình độ cao đẳng cao nhất đạt $69,3 \%$ và thấp nhất ở Trình độ sau đại học $17,9 \%$

2.5. Tỷ lệ tuân thủ thực hành vệ sinh tay theo khối điều trị

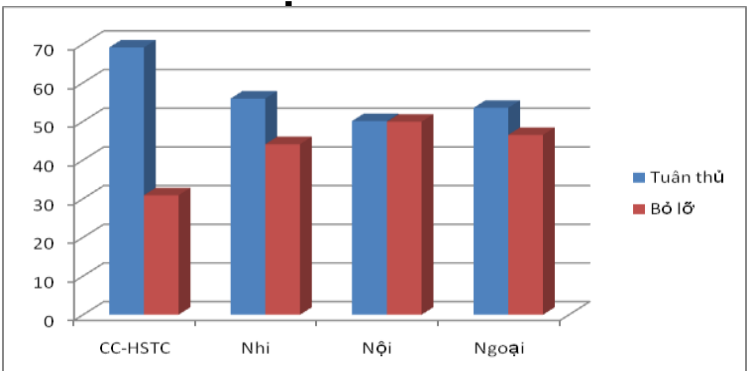

\section{Biểu đồ 3.3. Phân bổ tỷ lệ tuân thủ thực} hành theo khối điều trị

Nhân xét: Tỷ lệ tuân thủ thực hành VST ở khối Cẩp cứu - HSTC cao nhất đạt 69,1 \%, thấp nhất khối Nội đạt 50,6 \%.

2.6. Tỷ lệ tuân thủ thực hành vệ sinh tay theo khoa

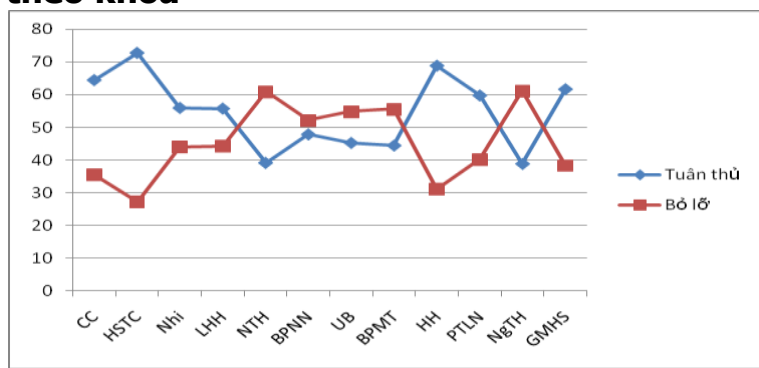

Biểu đồ 3.4. Phân bồ tỷ lệ tuân thủ thực hành VST theo khoa 
Nhân xét: Tỷ lê tuân thủ VST ở khoa Hồi sức tích cực cao nhất đạt 72,7 \%, thấp nhất ở khoa Ngoại tổng hợp đạt 38,8 \%

\section{BÀN LUÂN}

Qua kết quả đánh giá kiến thức NVYT về VST đều đạt trên trung bình và tỷ lệ khá, giỏi chung đạt $80,8 \%$, điều này cho thấy rằng NVYT tại Bệnh viện Phổi Trung ương nắm vững kiến thức vể VST.

Tỷ lệ tuân thủ thực hành VST chung ở cả 3 đối tượng $B S, ~ Đ D / K T V$ và $\mathrm{HL}$ đạt $55,9 \%$, tương đồng với kết quả nghiên cứu của Nguyễn Việt Hùng ${ }^{[5]}$ Bệnh viện Bạch Mai năm 2012 là 60,1\% và cao hơn kết quả nghiên cứu của Luc Thi Thu Quỳnh ${ }^{[4]}$ Bệnh viện Nhi Trung ương năm 2010 là $33,3 \%$ và của Phan Thị Hằng ${ }^{[6]}$ Bệnh viện Hùng Vương năm 2014-2015 là 43,6\%.

Tỷ lệ tuân thủ thực hành VST của BS thấp đạt $42,3 \%$, qua quan sát nhóm nghiên cứu nhận thấy BS do chưa được trang bị các phương tiện VST trong buồng bệnh khi khám bệnh, chữa bệnh, điều này cho thấy phương tiện VST có ảnh hưởng lớn đến tỷ lệ tuân thủ thực hành VST;

Tý lệ tuân thủ thực hành VST của $\mathrm{DD} / \mathrm{KTV}$ cao nhất đạt $59,6 \%$ do ĐD/KTV được trang bị đầy đủ các phương tiện VST trên xe tiêm, xe thủ thuật và xe thay băng..

Tỷ lệ tuân thủ thực hành ở Nữ $58,4 \%$ cao hơn Nam $48 \%$, điều này có thể do ý thức về VST của Nữ tốt hơn Nam;

Tỷ lệ tuân thủ thực hành VST ở thâm niên công tác < 10 năm đạt trên $70 \%$ và thâm niên $>20$ năm đạt dưới $26 \%$, kết quả nghiên cứu cho rằng NVYT mới công tác tại Bệnh viện chú trọng việc VST hơn NVYT có thâm niên > 20 năm;

Tỷ lệ tuân thủ thực hành VST ở trình độ cao đẳng là cao nhất đạt $69,3 \%$ và thấp nhất là trình độ sau Đại học đạt $17,9 \%$ kết quả này phù hợp với kết quả tuân thủ thực hành VST theo đối tượng. Trong đó trình độ cao đẳng chủ yếu là đối tượng ĐD/KTV do được trang bị đây đủ phương tiện VST, còn trình độ sau Đại học chỉ có ở đối tượng BS do chưa được trang bị phương tiện VST trong khám bệnh, chữa bệnh;

Tỷ lệ tuân thủ thực hành VST ở khối Cấp cứu - HSTC cao nhất đạt $69,1 / \%$, thấp nhất là khối Nội đạt 50,6\%; điều này có thể do NB ở khối Cấp cứu - Hồi sức tích cực chủ yếu là NB nặng, nguy cơ NKBV rất cao nển ý thức về tầm quan trọng VST tốt hơn ở khối Nội nên NVYT ở khối Nội còn lơ là trong việc tuân thủ thực hành VST.

Tỷ lệ tuân thủ thực hành VST của khoa cao nhất là khoa HSTC đạt 72,7\%, phù hợp với nhận xét về tính chất bệnh và nguy cơ NKBV cao của khối Cấp cứu - HSTC.

\section{KẾT LUẬN}

1. Tỷ lể kiến thức. Kiến thức của NVYT tại bệnh viện phổi Trung ương là khá tốt. Tỷ lệ đạt trên trung bình và tỷ lệ khá, giỏi ở bác sĩ, điều dưỡng, kĩ thuật viên và hộ lý đạt $>73 \%$

\section{Tỷ lệ tuân thủ VST}

- Tỷ lệ tuân thủ chung 55,9 \%

- Khoa Hồi sức tích cực có tỷ lệ tuân thủ thực hành VST cao nhất: $72,7 \%$

- Khoa Ngoại tổng hợp có tỷ lệ tuân thủ thực hành VST thấp nhất: 38,8 \%

- Tỷ lệ tuân thủ ở NVYT có thâm niên $<10$ năm trên 70\%, >20 năm dưới 26\%.

\section{KHUYẾN NGH!}

Tăng cường truyền thông thường xuyên, liên tục về vai trò và tầm quan trọng của việc VST và trang bị đầy đủ dung dịch sát khuẩn tay tại các vị trí khám chữa bệnh và tại các vị trí lavabo rửa tay.

Cần tiếp tục duy trì giám sát và phản hồi kết quả tuân thủ VST tại các khoa lâm sàng và cận lâm sàng mà trọng tâm là các khoa lâm sàng có người bệnh điều trị nôi trú trong bệnh viện.

Tiếp tục nghiên cứu đánh giá trong các năm sau để duy trì và nâng cao kiến thức, kĩ năng VST của nhân viên y tế

\section{TÀI LIỆU THAM KHẢO}

1. Nguyễ̂n Thị Thu Hà, Trân Đức Hùng và Kiêuu Chí Thành "Đánh giá kiến thức và khảo sát sự tuân thủ vệ sinh tay của nhân viên y tế tại một số khoa lâm sàng bệnh viện quân y 103 năm 2013" www.benhvien103.vn

2. Tài liệu đào tạo phòng và kiểm soát nhiễm khuẩn, Cục Quản lý Khảm chữa bệnh , Bộ Y tế, năm 2012

3. Vệ sinh tay trong phòng ngừa nhiễm khuẩn bệnh viện. Nhà xuất bản Y hợ Hà Nội 2010.

4. Lực Thị Thu Quỳnh, Nguyển Thị Hoài Thu, Lê Kiến Nágãi "Hiệu quả của một số chương trình thúc đầy tuân thủ vệ sinh tay tại Bệnh viện Nhi Trung ương" năm 2009-2010

5. Nguyê̂n Viêt Hùng "Nghiên cứu thực trang tuân thủ thực hành vệ sinh tay thường quy ở nhân viên y tế tại các khoa lâm sàng, Bệnh viện Bạch Mai năm 2012 - 2014".

6. Phan Thị Hằng, Trân Thị Thúy Hằng, Trân Thị Mỹ Hạnh, Christopher Gordon "Hiệu quả của chương trình huấn luyện, giám sát và phản hồi sự tuân thủ vệ sinh tay của nhân viên y tế", Bệnh viên Hùng Vương năm 2014-2015

7. WHO Guidelines on hand hygiene in heathcare. First Global patient safety challenge clean care is safe care 2009, Geneva.

8. Didier Pittet, Hugonnet $S$, Harbarth $S$, et al (2000), "Effectiveness of a hospital-wide programme to improve compliance with hand hygiene", Lancet, 356: 1307-1312. 